\title{
Visceral adiposity and cardiometabolic risks: epidemic of abdominal obesity in North America
}

This article was published in the following Dove Press journal:

Research and Reports in Endocrine Disorders

8 May 2013

Number of times this article has been viewed

\section{Sunil J Wimalawansa}

Robert Wood Johnson Medical School, University of Medicine and Dentistry of New Jersey, New Brunswick, NJ, USA
Correspondence: Sunil J Wimalawansa Robert Wood Johnson Medical School, University of Medicine and Dentistry of New Jersey, I Robert Wood Johnson

Place, New Brunswick, NJ 08903, USA

Tel +l 7322359584

Fax +l 7322358892

Email wimalawansa1@hotmail.com
Abstract: Over the past 40 years, the prevalence of obesity has more than doubled in the United States. Approximately 67\% of American adults older than 20 years of age are either obese or overweight. Obesity has now become a critically important issue facing more than $40 \%$ of Americans and has become a major burden on the American health care system. Today, obesity cannot be considered a simple lifestyle issue; it is a disease with major public health and economic consequences that requires serious attention by all stakeholders. Each individual has different causes and risk factors that lead to obesity and its associated complications. In addition to preventing becoming overweight, focusing on identifying the causes of obesity and then individualizing care and treatment plans to targeting weight loss, particularly intra-abdominal fat, could potentially generate huge cost savings. Excess intra-abdominal fat (visceral adiposity) is linked to excess morbidity and mortality, and positively correlates with the risks of insulin resistance, type 2 diabetes, cardiovascular diseases, certain cancers, and premature death. Therefore, overweight and obese patients should be offered healthy lifestyle changes including education about causes leading to excess weight, weight-reducing diets, physical activity regimens, and monitoring for progress. Medications and bariatric surgery are effective but are the last options and should be complementary to lifestyle and behavioral changes. The costs associated with managing obesity-related disorders and their complications are astounding; unless we intervene now, these are likely to triple over the next 2 decades. Thus, policymakers must pay serious attention to this progressive, insidious epidemic and determine the right paths for tackling obesity, which requires a paradigm shift in thinking and combined approaches. The increasing prevalence of obesity is a major health hazard in all health sectors, in both low and high income societies and countries. Thus, comprehensive programs are needed to minimize the effects of the epidemic.

Keywords: metabolism, epidemic, cytokines, body mass index, cardiovascular, overweight, obesity

\section{Introduction}

The current epidemic of obesity and type 2 diabetes (T2D) suggests that new nutritional and physical strategies are needed. Considering the staggering costs associated with the management of obesity and its complications, continuing with the current standard approach is not a fruitful option for the future. Before the Framingham Heart Study began in 1948, little was known about the epidemiology of cardiovascular diseases. ${ }^{1}$ Until the late 1970 s, obesity was not even considered a key risk factor for cardiovascular diseases. ${ }^{2}$ In the late 1980s, the American Heart Association suggested that there is evidence that obesity is a risk factor for cardiovascular disease, but the evidence is insufficient, and more research is needed. Nevertheless, over the past 2 
decades, a vast amount of knowledge has been accumulated, assisting in our understanding of the physical, social, emotional, and financial impact associated with being overweight and obese. ${ }^{3-6}$

By the law of conservation of energy, body fat increases when energy intake is consistently greater than energy expenditure, but genetics also plays an important role in weight gain. For most people who are overweight or obese, losing weight is difficult. Genetically based constructs, such as race and ethnicity are major influences, not only on biological distinctions and disease outcomes, but also on the prevalence of obesity and its complications. ${ }^{7-9}$ Changing environmental factors constantly interact and influence these constructs. For the majority of patients, behaviors are the key reason for the excessive accumulation of body fat. Therefore, healthy lifestyle choices are one of the best options by which to prevent obesity, reduce excessive body weight after it has developed, and to maintain body weight at a healthy level. ${ }^{10}$

\section{Epidemiology of obesity}

Over the past 4 decades, the incidence of obesity has continued to increase across the United States and worldwide. ${ }^{1-13}$ At the current rate of increase and the sheer number of people affected with obesity, deaths due to complications associated with obesity are likely to surpass deaths attributable to cardiovascular diseases (CVD) within the next 2 decades. These obesity-associated comorbidities include insulin resistance, metabolic syndrome, T2D, strokes, dyslipidemia, hypertension, coronary artery disease, certain cancers, chronic kidney disease, osteoarthritis, sleep apnea, and premature death. However, many Americans do not seem to grasp the seriousness of this epidemic and its longterm consequences. ${ }^{14}$ Historically, the term "pandemic" was used to describe out-of-control, serious infections that kill millions. Nevertheless, unless serious, effective and and sustainable public health measures are taken, obesity associated complications and deaths will become a pandemic issue. In fact, they are likely to become the number one killer in both eastern and western countries.

The United States Department of Health Statistics published a report on the prevalence of adult obesity in Canada and the US. ${ }^{15}$ The US systematically collected anthropometric and other statistical data, starting in the 1960s, via the National Health and Nutrition Examination Survey, but Canada has only had such a mechanism since 2007 when it began to use the Canadian Health Measures Survey. ${ }^{16}$ This data demonstrated that, between 2007 and 2009, the prevalence of obesity in Canada was $24.1 \%$, whereas in the US it was approximately $34.4 \% .{ }^{17}$ Although there are baseline differences in the prevalence of obesity in the US and Canada, the increases in prevalence over time appears similar, which suggests that similar causes contribute to the obesity epidemic in North America. According to the 2009 Center for Disease Control disease prevalence data, Department of Health and Human Services, Office of Minority Health, ${ }^{18}$ African Americans are 1.5 times more likely to be obese than non-Hispanic whites, while Native Americans and American Indians/Alaskan Natives are 1.6 times more likely to be obese than non-Hispanic whites. ${ }^{18}$

The higher the body mass index (BMI), the greater the likelihood of associated comorbidities. T2D is perhaps the most serious because it leads to multiple serious complications, including premature death. According to the Nurses' Health Study data, the risk of diabetes is 50- to 60-fold higher when BMI is greater than $35 \mathrm{~kg} / \mathrm{m}^{2,19}$ From a nonfinancial perspective, BMI negatively correlates with quality of life ${ }^{20}$ positively with and mortality. ${ }^{21,22}$ The number of problems associated with being overweight is numerous, but the most serious comorbidities are metabolic syndrome, hypertension, dyslipidemia (high quantities of triglycerides, and low-density lipoprotein [LDL]) and lower amounts of highdensity lipoprotein [HDL], T2D, cardiovascular disease, stroke, myocardial infarction, peripheral vascular disease, cancer, and sleep apnea.

Visceral adiposity correlates with the risk of development and the severity of T2D, insulin resistance, and CVD. ${ }^{23-25}$ Obese individuals with excess deposition of intra-abdominal (visceral) fat and dyslipidemia are the ones with the greatest risk of developing CVD. ${ }^{26}$ In addition to the medical and personal costs, the opportunity costs due to loss of productivity and costs secondary to obesity are considerable. Accurate direct financial estimates of managing obesity are difficult to determine, but a decade ago researchers reported direct medical costs of managing diabetes to be approximately US\$92 billion in the US. ${ }^{27-29}$ Taking into account the escalating incidence of obesity and T2D along with the costs of new technology and treatments, this figure has likely more than doubled by 2013 .

\section{Cost of managing obesity}

An effective prevention and treatment program that targets healthy and sustainable weight would improve morbidity and mortality rates and facilitate controlling the escalating health care costs associated with overweight and obesity. The medical costs attributable to obesity alone were approximately US\$78 billion in 2003, half of which 
was incurred by the US government through Medicare or Medicaid benefits. ${ }^{30}$ Estimates of such costs have escalated to more than US\$180 billion a year over the last decade. ${ }^{31,32}$

Studies have reported that the combined use of BMI and waist circumference (WC) is not better than using the latter alone in identification of high-risk persons, because in part the BMI does not capture visceral fat. ${ }^{33-36}$ Meanwhile, interventions that achieve a sustainable weight loss in the range of $7 \%$ to $10 \%$ of initial body weight are known to cause significant reduction in the cardiometabolic risks and obesity-associated conditions, including T2D, hyperlipidemia, and hypertension, and hard outcomes such as stroke, myocardial infarction, and death. ${ }^{22,32}$ Thus, lowering excess weight in obese patients has major beneficial outcomes, including improving quality of life and cost reductions. In this regard, nonrandomized studies of obese patients treated with fenfluramine/mazindol, fenfluramine/phentermine, caffeine/ephedrine, or mazindol for weight loss reported that the pharmaceutical cost savings arising from a reduced need for medications to treat diabetes, dyslipidemia, and hypertension because of weight loss more than offset the cost of the weight-loss medications. ${ }^{37}$

The escalating incidence of obesity was first noted about 4 decades ago. At first, obesity was recognized as a symptom that occurs as a result of accumulation of excess intake of energy as fat, but not as a disease. This view has changed, and most scientific organizations worldwide now identify obesity as a specific disease entity. ${ }^{38,39}$ Like other metabolic disorders, obesity consists of various pathological, inflammatory, and endocrine entities (excess production of inflammatory adipocyte hormones and cytokines) and a pathophysiology (lifestyle and an environmentally inducible dysregulation of appetite and bodyweight controlling mechanisms). ${ }^{40}$ Therefore, to tackle obesity properly in a cost effective manner, it is essential to accept obesity as a disease. Doing so would also minimize the stigma associated with the condition and allow wider acceptance of public preventative efforts, incorporation of nutrition and physical activity into school curricula, portion control especially of fried and sugary foods and drinks, improved access to sustainable behavioral changes and treatment, and appropriate resource allocation for prevention and treatment.

Classifying obesity as a disease would decrease the perception of patient responsibility for managing weight. It also could bring together partnerships of the private and public sectors, pooling resources for cost effective preventative and curative medical care for managing risk factors for CVD and T2D, rather than spending vast amounts of funds to treat the end stage complications associated with obesity. Weight reduction facilitates decreasing several important independent cardiometabolic risk factors, and thus has a major impact on decreasing $\mathrm{CVD},{ }^{41}$ whereas spending efforts and resources to treat individual risk factors separately is expensive and has lesser impact on reducing overall CVD.

\section{Obesity, the most rapidly spreading disease in the US}

Over the past 3 decades, obesity and associated diseases have rapidly increased in North America and worldwide. ${ }^{42,43}$ Among men in the US, obesity increased significantly from $27.5 \%$ to $31.1 \%$ between the period $1999-2000$ and 2003-2004; for women, it was different (33.4\% in 2000 versus $33.2 \%$ in 2003-2004) during that period. Overall, $32.2 \%$ of adults were obese in $2003-2004,{ }^{42}$ and extreme obesity (BMI > 40) was observed in $2.8 \%$ of men and $6.9 \%$ of women.

Racial differences in obesity prevalence have also been noted; ${ }^{43}$ for example, $30 \%$ of non-Hispanic white adults are considered obese, compared to $45 \%$ of non-Hispanic blacks and $36.8 \%$ of Hispanic adults. The prevalence of overweight female children and adolescents increased from $13.8 \%$ in $1999-2000$ to $16.0 \%$ in $2003-2004 .^{43}$ Likewise, the prevalence of overweight male children and adolescents increased from $14.0 \%$ in $1999-2000$ to $18.2 \%$ in 2003-2004. Over the past decade, a significant increase in obesity prevalence has been reported among males aged 2 through 19 years, but not in females. In 2009-2010, the prevalence of obesity in children and adolescents was $16.9 \%{ }^{44,45}$

The percentage of Americans who are classified as overweight (defined as BMI $\geq 25 \mathrm{~kg} / \mathrm{m}^{2}$ ) or obese (defined as BMI $\left.\geq 30 \mathrm{~kg} / \mathrm{m}^{2}\right)$ have significantly increased $(P<0.001)$, from $55.9 \%$ in the third National Health and Nutrition Examination Survey, which tracked rates of overweight and obesity in the years 1984-1992, to $64.5 \%$ in a National Health and Nutrition Examination Survey analysis for $1999-2000 .^{11,46,47}$ The prevalence of those progressing from overweight to obese has more than doubled over the past 4 decades; $13.4 \%$ in 1960 to $31.0 \%$ in 2000 in the US population. ${ }^{48}$ Currently, $67 \%$ of US adults older than 20 years are overweight or obese. ${ }^{44,47,50}$

These trends have major health care and socioeconomic implications because obesity and its associated metabolic derangements are directly related to increased risks for T2D, hypertension, heart disease, sleep apnea, cancer, nonalcoholic fatty liver, cholelithiasis, arthritis, and infertility; these are costly diseases to manage and are independent predictors of mortality. ${ }^{42,43,51-60}$ This epidemic clearly requires a paradigm shift from viewing obesity not as only a simple lifestyle issue, but recognizing it as a disorder with major public health and 
economic concerns. This is important not only for appropriate resource allocation and cost management, but also the huge loss of productivity that is linked to comorbidities and the shortening of longevity. Some statistical projections use life expectancy at birth, which is generally used to proxy a country's health and poverty, but seems less accurate for an industrialized economy. However, the productivity parameters and absenteeism must consider the limitations of applying the statistical data results to GIVmarket (Northumberland, UK). ${ }^{61,62}$

\section{Major health risks of obesity}

Obesity is a serious health hazard and a major risk factor for CVD and T2D, and contributes substantially to morbidity and premature mortality. ${ }^{42,43}$ Simplified assessment tools, including $\mathrm{BMI}$ and WC thresholds, have been developed to diagnose overweight and obesity in clinical practice. However, these tools are underused, and, thus, patients are not receiving early diagnosis and interventions that are needed to reduce their health risks. Public awareness of the health risks associated with overweight and obesity should be heightened so that healthy weight management garners the attention it deserves in mainstream medical care.

More than $40 \%$ of children born in the new millennium in the US are predicted to become obese during their lifetimes. ${ }^{9,47,63}$ Therefore, unless corrective actions are taken now, the prevalence is likely to increase in the years to come. ${ }^{10,64-66}$ Because obesity develops over several years, many children and adults do not realize the issue of becoming overweight until symptoms appear. ${ }^{67}$ Some of these signs and symptoms, at least initially, can be subtle, but others can be obvious, including abnormal weight gain and hunger, nutritional deficiencies, abnormal eating habits, constant fatigue, respiratory and digestive issues, sleep apnea, decreased mobility due to osteoarthritis (joint and back pain), and signs and symptoms of T2D.

If unrecognized or unattended, many of these patients eventually will experience complications, including tooth decay and gum disease, frequent infections (particularly in the skin), sleep disorders, and lung and urinary tract disorders. Others will experience ominous micro- and macrovascular complications secondary to insulin resistance and T2D, including nephropathy, retinopathy, peripheral and autonomic neuropathy, and premature death mostly attributable to cardiovascular and cerebrovascular disorders.

Despite wide publicity and ongoing research, it is difficult to pinpoint the exact causative factor(s) for the current pandemic, which continues to threaten many lives across the world. Although some believe that the recent epidemic of obesity is due to an unknown new factor or epigenetic variant, the prevailing data suggest it is a mostly due to a combination of two key issues: (1) unhealthful eating habits and consumption of calorie-dense diets; and (2) inadequate physical activity. However, obesity is not the only reason people have T2D, and not all individuals with obesity have T2D, and not every patient with T2D is obese; for example, those with lipodystrophy, a condition with near absence of fatty tissue, can have T2D. ${ }^{68,69}$

\section{Pathophysiology of obesity}

It has been hypothesized that a growing fetus exposed to poor maternal nutrition or placental dysfunction is capable of adapting to maximize its future survival. ${ }^{70-72}$ Such adaptation of metabolic programming includes the proliferation of fat cells to enhance future fat storage of nutrients and to face potential adverse environmental conditions in later life. This survival programming established in utero is thought to enable humans to survive during future episodes of famines and malnutrition. ${ }^{73}$

However, in the presence of plentiful food availability and less physical activity, these epigenetic changes and the evolutionary survival advantage could lead to excessive fat storage, and the development of obesity and the consequent T2D. Thus, when a person continues consuming excess calories in the presence of less physical activity, obesity and insulin resistance is likely to develop, which may then predispose obese patients to develop T2D. Some have the capacity to develop adaptive-thermogenesis, which prevent them gaining weight with increased caloric intake. Those who do not have such compensatory ability are likely to gain weight following excess energy intake. ${ }^{73}$ However, it seems that the incidence of these aliments is higher in those who were exposed to intra uterine malnutrition than in those who were not affected. ${ }^{74}$ This thrifty phenotype hypothesis also suggests that in the event of under nutrition, the brain is spared at the expense of other tissues, including the endocrine pancreas. ${ }^{73,75-77}$ Data also suggest that poor in utero growth correlates with the increased risk of T2D in adulthood. ${ }^{77,78}$

Low-birth-weight children not only have significantly lower levels of serum adeponectin levels, ${ }^{79}$ but also such gestations have been linked to the increased risk of metabolic syndrome in later life.$^{80,81}$ Moreover, the rapid weight gain during the first 3 months after birth, perhaps via increasing fat cell numbers, may also be associated with higher prevalence of metabolic syndrome in later life. ${ }^{82,83}$ Therefore, the risks associated with genetics, development, and environment in particualr secondary to toxins, all can precipitate or exacerbate cardiometabolic risk in later life.

It is hypothesized that, in the presence of maternal protein restriction, there would be a lesser number of pancreatic beta cells and smaller islets in the offspring, and thus lower amounts of insulin secretion and thus, impaired function of pancreatic 
beta cells in response to glucose and amino acid loads. It has also been postulated that this insulin resistance observed in the offspring of those mothers with low protein intake may be related to postreceptor defects. ${ }^{84}$ Irrespective of the underlying pathology, the inability of the pancreas to secrete appropriate amounts of insulin in response to a meal leads to hyperglycemia, hyperlipidemia, and metabolic and biochemical abnormalities. Consequently, the body is unable to process glucose and fatty acids appropriately to generate energy and handle other nutrients physiologically that lead to glucotoxicity and lipotoxicity. ${ }^{85,86}$

The development of T2D is insidious; however the development of macro vascular complications starts before the diagnostic clinical manifestation of hyperglycemia. ${ }^{87,88}$ In addition to the development of insulin resistance, glucotoxicity and lipotoxicity continue to damage beta cells and thus further reduce insulin production. ${ }^{89}$ The inability of tissues to use insulin efficiently hampers the conversion of glucose into energy and the entry of fatty acids into to muscle cells. Consequently, a vicious cycle of hyperglycemia and hyperlipidemia develops, leading to glucotoxicity, lipotoxicity, and abnormal lipid metabolism and an accumulation of visceral fat and excess lipids in the arterial walls that tend to get oxidized leading to atheroma formation..$^{90}$ The presence of abdominal obesity and metabolic syndrome worsen the outcomes of T2D, including a markedly increased risk of CVD deaths and stroke. ${ }^{91}$

\section{The role of fat cells and inflammation in obesity and CVD}

The human body has limited capacity to generate new fat cells. A $70 \mathrm{~kg}$ person is thought to have between 35 and 50 billion fat cells distributed between subcutaneous tissues and in the abdominal cavity. Thus, as a person becomes overweight and T2D manifests, the ingested excess energy will be stored as fat in the existing fat cells by becoming hypertrophic. However, once fat cells exceed their capacity to intake circulating lipids, they will be enhance secreting a variety of inflammatory cytokins and, eventually engulfed by macrophages. Consequently, fat begin to deposit in extracellular tissues, such as muscle and liver, and in the vasuclar walls, starting a inflammatory vicious cycle. Hyperlipidemia and insulin resistance would further aggravate, and the development of atherosclerosis and associated complications manifest.

Hypertrophied fat cells, particularly in intra-abdominal visceral fat cells, produce increasing amounts of a number of chemicals and cytokines that cause systemic inflammation. Moreover, these cytokines drain directly into the liver via the portal vein, thus exposing the liver to high levels of inflammatory agents. These potent inflammatory signals increase the hepatic production of C-reactive protein, interleukins, and tumor necrosis factor alpha (TNF- $\alpha$ ), elevated levels are a common findings in obese patients. ${ }^{92}$ Excess circulatory fats not only accumulate in the visceral fat cells, but also in the liver, leading to steatohepatitis and nonalcoholic fatty liver disease, which precedes the development of cirrhosis. Excess fatty acids further aggravate insulin resistance and abnormalities in other tissues, including the development of fatty streaks and formation of atheromatus plaques in the arterial walls.

Meanwhile, fat infiltration in muscle and liver cells further increase insulin resistance and deranges intra-cellular metabolism. Among others, epigenetic changes and the glucotoxicity continues to damage endothelial cells and pancreatic beta cells, which is exacerbated by the ongoing chronic inflammation (eg, insulitis) and amyloid deposits in the pancreas, leading to further reduction in insulin production and release, thereby worsening insulin resistance and diabetes.

In evolutionary terms, humans are designed to have proinflammatory cytokines as natural defensive responses to combat infections. However, in an individual with obesity and/or diabetes, because of the continued and enhanced inflammatory responses triggered by these cytokines and their effects on key organs including the liver, a serious negative cycle is established. Overburdened intra-abdominal fat cells act as a continual source of generalized chronic inflammation. Inflammation continues secondary to the constant release of inflammatory cytokines and the suppression of anti-inflammatory cytokines from hypertrophied fat cells that are directly drained into the liver. ${ }^{92}$ This is detrimental to hepatocytes and overall health, and is a key factor of CVD, hepatic steatosis, and premature death.

\section{Fat, energy, and survival}

Stored fat is designed to release energy to cover the day-to-day energy requirements and, more importantly, allow humans to survive in the event of food scarcity and starvation. In obese patients, the accumulation of visceral fat and the increase of insulin resistance, and the consequent development of T2D, causes the opposite of survival. Metabolic paths are designed to take up excess fat when humans have abundant food and release these fats as a source of energy when food is scarce: a key evolutionary survival mechanism. However, major lifestyle changes over the past 4 decades, especially in industrialized countries with easy access to energy-dense, unhealthy food, including fast food and sugary soft drinks, together with less physical activity, contributing to this maladaptation of energy metabolism and pathological energy storage. Most fast food, 
processed and packaged food also contain unhealthy fats (trans fat and saturated fat), cane- and corn-syrup-enriched sugars, excess salt, and chemical preservatives that are harmful, and alter human physiology into a pathological processes.

Frequent intake of high glycemic and lipemic, energydense, cheaper food leads to rapid absorption of sugar and fatty acids, exaggerated surges of insulin, and rapid absorption and release of excess fatty acids into the circulation. However, the human body and its physiological mechanisms are not designed to handle these rapid influxes of sugar and fatty acids and the peaking of insulin within short periods. Thus, in this pathological situation, energy sources are not directed to muscle cells for metabolism but are driven into liver and fat cells, especially into visceral fat cells.

In addition to these negative dietary consequences, lifestyle changes attributable to convenience and ease of transportation have further decreased physical activity in recent years. Taken together, for an average person who is working at a desk job, the large portion sizes (particularly with reference to foods with high salt, fat, and/or sugar content) and large-size high-caloric beverages, and moving away from healthful, traditional, nutrient-rich diets that contain a balance of minerals, micronutrients, vitamins, and fiber, contribute to the current obesity epidemic.

\section{Defining obesity and decreasing the CVD risks in clinical practice}

From a physiologic standpoint, obesity is the result of an imbalance between energy intake and energy expenditure. The increase in body weight associated with overconsumption of food and less physical activity occurs mainly in the form of fat, and to a lesser extent, lean mass. Moreover, the components of the energy balance are also influenced by social, cultural, and behavioral factors.

The health risks associated with obesity also depend on the distribution of body fat. Although the accumulation of visceral body fat is harmful and contributes substantially to morbidity and premature mortality, subcutaneous fat may not be. Consequently, assessment tools that have been developed to diagnose overweight and obesity in clinical practice, like BMI, may not capture those with predominant abdominal obesity, but measurements such as WC or waist-to-hip ratio would. Nevertheless, the combination of these two easily implemented tools may be better than individual measures in identifying those who are at risk of developing complications. In spite of this, these simple tools are underused, thus patients do not receive early diagnosis and intervention, and this delays the preventative measures needed to reduce their future health risks.
Table I Waist circumference thresholds to define abdominal obesity

\begin{tabular}{lll}
\hline $\begin{array}{l}\text { Region/ } \\
\text { ethnicity }\end{array}$ & $\begin{array}{l}\text { Recommending } \\
\text { body }\end{array}$ & $\begin{array}{l}\text { Waist circumference threshold } \\
\text { for abdominal obesity }\end{array}$ \\
\hline $\begin{array}{l}\text { United } \\
\text { States }\end{array}$ & AHA/NHLBI & $\geq 102 \mathrm{~cm}$ in men; $\geq 88 \mathrm{~cm}$ in women ${ }^{\mathrm{b}}$ \\
$\begin{array}{l}\text { Europe/ } \\
\text { Europids }\end{array}$ & IDF & $\geq 94 \mathrm{~cm}$ in men; $\geq 80 \mathrm{~cm}$ in women \\
Asia & AHA/NHLBI/IDF & $\geq 90 \mathrm{~cm}$ in men; $\geq 80 \mathrm{~cm}$ in women ${ }^{c}$
\end{tabular}

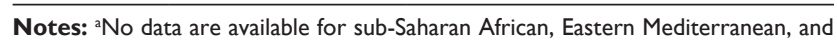
Middle Eastern populations, nor ethnic South and Central Americans. IDF suggests using waist thresholds for Europe/Europids for populations in these regions; ${ }^{\mathrm{b}} \mathrm{AHA} /$ NHLBI guidelines indicate that waist thresholds of $\geq 94 \mathrm{~cm}$ in men and $\geq 80 \mathrm{~cm}$ in women are optional criteria in persons who show clinical evidence of insulin resistance; In Japan and southeast Asian countries, recommendations for waist circumference thresholds for abdominal obesity are $\geq 90 \mathrm{~cm}$ in men and $\geq 80 \mathrm{~cm}$ in women. ${ }^{80}$

Abbreviations: AHA/NHLBI, American Heart Association/National Heart Lung and Blood Institute; IDF, International Diabetes Federation.

Measurements of the $\mathrm{WC}$ and waist/hip ratio are simple and easy methods and useful markers by which to identify those who are at a higher risk. WC is measured just above the pelvis with the tape measure kept parallel to the ground, excluding the pannus. Because the measurement also encompasses visceral body fat, it is a better predictor of insulin resistance, as well as morbidity and mortality, independent of BMI. ${ }^{93-95}$ In fact, WC can identify those who are at a high risk of T2D, which is independent of BMI and other common cardiovascular risk factors. ${ }^{95}$ Another simple measure is the waist-to-height ratio; keeping the WC less than half of the height. Phenotypes with excess intra-abdominal fat are referred to as the hypertriglyceridemic waist. ${ }^{96}$ Moreover, the quantity of visceral fat explains the positive association between the visceral fat (thus, WC) and morbidity. ${ }^{24}$

The International Diabetes Federation ${ }^{73}$ modified criteria for the clinical diagnosis of metabolic syndrome include having (1) insulin resistance; (2) $\mathrm{WC} \geq 94 \mathrm{~cm}$ in men and $\geq 80 \mathrm{~cm}$ in women (Caucasians, Europids, sub-Saharan Africans, and Middle Easterners) and a $\mathrm{WC} \geq 85 \mathrm{~cm}$ in men or $\geq 78 \mathrm{~cm}$ in women (Asians, including Japanese, and South and Central Americans [Table 1]); and (3) having any two of the following: fasting triglycerides $\geq 150 \mathrm{mg} / \mathrm{dL}$; HDL cholesterol $<40 \mathrm{mg} / \mathrm{dL}$ in men or $<50 \mathrm{mg} / \mathrm{dL}$ in women; systolic blood pressure $\geq 130 \mathrm{mmHg}$ or diastolic $\geq 85 \mathrm{mmHg}$; fasting blood sugar $\geq 100 \mathrm{mg} / \mathrm{dL}$; or having diabetes.

\section{The importance of body fat distribution}

Excess accumulation of visceral body fat bestows cardiometabolic risks. The amount of body fat itself is a risk factor, but the distribution of body fat, particularly visceral fat, is a better measure of CVD risks. ${ }^{33}$ Because BMI does not capture 
the visceral body fat component, there are limitations in using the BMI for diagnosis and assessing the cardiometabolic risks in obese persons, particularly in certain ethnic groups, as indicated in Table 1. Therefore, two people with similar BMIs and of the same sex, age, and height can have very different phenotypes and presentations, depending on body fat distribution (central [obese and unfit] versus peripheral [obese and fit] distribution).

A person with excess fat in peripheral tissues (accumulation of subcutaneous fat) may have normal blood pressure, blood glucose, and lipid panel, whereas a person with central obesity is likely to present with impaired glucose tolerance, hypertension, dyslipidemia, insulin resistance, and premature coronary artery disease; these are key variations that would lead to markedly different health outcomes. These differences are mostly attributable to the distribution and the differential pathophysiological responses of the body fat, but also and to a lesser degree, to their personal habits. Adipose tissue in the upper versus lower part of the body has different metabolic properties. The upper body adipocyte is typically resistant to the antilipolytic effects of insulin and sensitive to the lipolytic effects of epinephrine, whereas the lower body fat cell tends to be more sensitive to insulin and relatively resistant to epinephrine..$^{97,98}$

\section{The value of measuring WC}

The ability of BMI to predict the risk of CVD or mortality risk is inconsistent. While in Caucasians, BMI is a reasonable measurement to identify potential health risks, additional measurements are needed in other ethnic groups, including Asians, as BMI is not a good predictor of the CVD risk or mortality. ${ }^{99,100}$ Abdominal obesity, as measured by WC, waist-to-height ratio, or waist-to-hip ratio, reflects increased health risks and disability, ${ }^{101,102}$ and are more accurately than does BMI alone, and is a stronger indicator of obesity-related CVD risks. ${ }^{99-110}$ Consequently, these simple measures should be adapted as clinical components in the routine assessment and management of metabolic and cardiovascular risks. ${ }^{96,103,106-108}$

There are several expensive, glamorous, high-tech tests available to identify those who are at risk of CVD, including computerized tomography or magnetic resonance imaging based quantification of visceral fat, subfractionation of serum lipids, coronary calcification scores via multislice computed tomography, and so forth; but none of these options are cost effective. Despite the sophistication and high cost of these methods, they are at best only marginally better than the information generated from measuring the abdominal girth at baseline and monitoring it longitudinally. In fact, for most patients, visceral adiposity as determined by increased abdominal girth indicates their poor health status and potential negative future outcomes. ${ }^{108}$

The gradual decrease of abdominal girth, rather than focusing on weight loss alone, should be used to positively reinforce obese patients in their attempts to lose weight, particularly with Asian patients. It should be measured in all patients, using a tape measure across the abdomen using the same reference point, and documented at each visit. With reference to future CVD outcomes, abdominal girth measurements are more sensitive than calculated BMI, particularly in South Asians. ${ }^{106,110-112}$ Compared to those with peripheral obesity, those with abdominal obesity with excess visceral adiposity have a higher prevalence of atherogenic dyslipidemia, inflammation, insulin resistance, and coronary artery disease. Thus, regardless of sex, simple measurements of abdominal girth, blood pressure, and a basic serum lipid profile seem to be the most cost effective way to identify those who are at a higher risk of metabolic syndrome, insulin resistance, and CVD.

Epidemiologic studies have suggested that the standard established with WC in both men and women for white Caucasians cannot be applied to other ethnic groups, in particular in Asians (Table 1). ${ }^{103,110}$ An isolated increase of fasting triglyceride levels in the absence of increased WCs are relatively benign and may correlates with the amount of subcutaneous fat; thus, requirement and the approach for therapy is likely to be different from those with abdominal obesity. Such patients may not have poor prognostic genotype, compared to patients with central adiposity, especially if they are physically active and have a rather healthy diet and lifestyle. They are also more insulin-sensitive than patients with visceral obesity. On the other hand, for those with increased WC, even if the BMI is within the normal range, hypertriglyceridemia indicates as an important risk factor for insulin resistance, T2D, a high incidence of coronary artery disease and premature death.

A number of metabolic studies have confirmed that among equally obese patients, subjects with excess visceral adiposity have the highest metabolic risks, ${ }^{112,113}$ including insulin resistance and compensatory hyperinsulinemia. In those who are genetically susceptible, this condition favors more fat diversions to the visceral fat cells, leading to chronic and sustained inflammation and the development of glucose intolerance, insulin resistance, and T2D. ${ }^{114}$

In Caucasians, Latinos, and African-Americans, the use of BMI is an easy and reliable guide for assessing obesity and predicting the probability of future ill health. Asians in particular have a relative lack of subcutaneous fat with a tendency to develop excess visceral abnormal adipose tissue phenotype, low HDL, and high triglycerides. Thus, BMI by itself is a poor indicator of CVD risk, and is not applicable to 
most Asians, and the use of WC or the waist-to-hip ratio is better in identifying those who are at risk. In Asians, insulin resistance and metabolic syndrome can be demonstrated with a BMI of as little as 23 , thus the abdominal girth is more sensitive in identifying those with insulin resistance and the metabolic syndrome. In Asians, abdominal girths of more than 34 inches $(85 \mathrm{~cm})$ in women and 36 inches $(90 \mathrm{~cm})$ in men (Table 1) are highly likely to be associated with insulin resistance and metabolic syndrome, regardless of BMI.

\section{Cardiometabolic risks associated with obesity}

The visceral fat contents are positively correlated with the cardiometabolic risks and leading to the development of CVD. Cardiometabolic risks are clustered in patients with obesity and T2D, and these diseases are interlinked. They are associated with the common phenomenon of increased risk of coronary disease, cardiovascular events, stroke, and premature death. Both are intertwined with the features of metabolic syndrome: insulin resistance, increased WC, elevated serum triglyceride concentrations, low levels of HDL cholesterol, high levels of small dense LDL, high blood pressure, and high levels of fasting glucose. These confer additional excess risks beyond the classic risk factors, such as low levels of HDL cholesterol, high non-HDL cholesterol, smoking, and hypertension, which physicians are quite familiar with treating.

Controlling cardiometabolic risk by addressing hypertension, dyslipidemia, and T2D is important, but these can be more effectively addressed as a cluster by focusing on weight reduction. Such approach to treating people with abdominal obesity - those who are obese and sick - would lead to decreases in all risk factors, and minimiz all adverse outcomes in patients with obesity and T2D. Thus, clinicians who treat patients for cardiovascular complications must be mindful of the inherent metabolic risks, including insulin resistance, as precursors to T2D in obese patients with excess visceral adiposity. Similarly, health care workers who treat obese patients and patients with T2D should attempt to normalize their patients' weight, and screen their patients for CVD risk factors with the view of decreasing long-term negative consequences.

\section{Visceral adiposity and cardiometabolic risk}

In addition to being less productive and being frequently absent from work, obese patients consume more health care resources. However, not all patients with obesity develop metabolic syndrome or its complications. In fact, some obese patients do not have a higher risk of CVD and may never develop associated potential complications, whereas others have greater incidences of T2D, dyslipidemia, hypertension, insulin resistance, strokes, and coronary artery disease. ${ }^{51-53,115}$ This heterogeneity of obesity is attributable in part to genetic inheritance and to the pattern of distribution of fat within the body, in particular to the compartmentalization of fat in the subcutaneous tissues versus the intra-abdominal area. The key is to identify those who are at high risk and provide better preventative and curative care for them.

The accumulation of excessive visceral fat leads to insulin resistance and abnormal lipid metabolism, leading to dyslipidemia, including hypertriglyceridemia, low HDL cholesterol, and elevated apolipoprotein B, increased levels of remnants of triglyceride rich lipoproteins, and a shift in the distribution of LDL into smaller more dense particles, even in the absence of hyperglycemia or glucose intolerance. ${ }^{26,116}$ In addition to the dyslipidemia and insulin resistance, patients with visceral obesity also have other metabolic abnormalities, including endothelial dysfunction, chronic inflammation impaired fibrinolysis, and coagulation abnormalities that lead to an increased tendency to thrombosis. ${ }^{52,117,118}$

In addition, visceral obesity and hyperinsulinemia are often associated with elevated apolipoprotein B and small atherogenic non-HDL particles in circulation (lipoproteins that are markers of increased atherogenic potentials) and are at a higher risk of CVD. ${ }^{119}$ People with such characteristics are likely to have a more than 10-fold higher risk for CVD with increased likelihood of premature death, regardless of age or sex. Therefore, in addition to minimizing risk factors, it is necessary to develop more refined and sensitive, but affordable and easily measurable, biochemical markers to identify those who are at risk at an earlier stage of this disease process, enabling reversal of this negative vicious cycle. ${ }^{36}$

\section{Visceral obesity and metabolic syndrome}

Excess visceral adipose tissue is associated with insulin resistance and metabolic abnormalities that increase the risk of T2D and CVD. ${ }^{120}$ However, whether the visceral adipose tissues and chemicals released from these fat cells are causally involved in the metabolic abnormalities found in obese patients is not clear. Bypassing the stomach and duodenum via bariatric surgery can significantly ameliorate T2D and metabolic syndrome in many patients, so it may not be simply the abdominal fat per se that causes these multiple metabolic abnormalities. ${ }^{121-123}$ Current data suggest that this is a complex process that involves an imbalance of chemicals and hormones released from the enteric, cerebral, and neurointestinal systems. ${ }^{71}$ 
Visceral adipose tissue is hyperlipolytic and is more resistant to the antilipolytic effect of insulin than is subcutaneous fat. ${ }^{124}$ The venous blood from the omental fat in the abdomen drains directly into the liver via the portal vein, thus exposing the liver to high concentrations of free fatty acids and inflammatory cytokines, major contributors for the generation of hepatic inflammation and C-reactive protein, fatty liver, and steatohepatitis of nonalcoholic fatty liver disease. This vicious negative cycle further impairs liver function, increases hepatic glucose production and overproduction of apolipoprotein B containing triglyceride rich lipoproteins, and impairs hepatic uptake of insulin, which exacerbates hyperinsulinemia and increases gluconeogenesis. ${ }^{125}$ This metabolic derangement leads to hyperinsulinemia, hyperglycemia, hypertriglyceridemia, and increased apolipoprotein $\mathrm{B}$, which are hallmarks of patients with visceral obesity.

Visceral adipose tissue should be considered as an endocrine organ and is a key site of production of inflammatory cytokines when over-burdened fat cells and macropharge cells are activated by a pathological system. ${ }^{126}$ These include interleukin 6 and TNF- $\beta$. The circulatory protective cytokine, adiponectin, mostly comes from peripheral fat tissues ${ }^{127,128}$ and its production is inversely related to the content of visceral fat. Nevertheless, the hyperlipolytic state of visceral fat alone cannot explain all metabolic abnormalities observed in viscerally obese patients. ${ }^{129}$

Higher levels of circulatory CRP also are known to be associated with inflammation. In fact, high circulatory CRP levels are associated with increased WC and the accumulation of visceral adipose tissue, ${ }^{52}$ an indicator of chronic inflammation. Multivariate analyses have demonstrated that WC is by far the best predictor of individual differences in CRP concentrations. ${ }^{130}$ These high correlations seem to be attributable to the enhanced production of inflammatory cytokines derived from visceral fat cells. ${ }^{131}$ Macrophages are known to infiltrate adipose tissues, including the vascular walls and visceral fat tissues. ${ }^{132}$ In addition to the overloaded visceral fat cells, these infiltrating, activated macrophages themselves are a major source of the generation of inflammatory cytokines, including TNF- $\alpha$ and interleukin 6 , which further exacerbate metabolic abnormalities. ${ }^{133-136}$

Either too little or too high estrogen levels in both sexes can cause not only a multitude of metabolic abnormalities but also cancers. Estrogen at appropriate physiological levels has a protective role in energy conservation and body fat distribution. Consequently, postmenopausal women with the cessation ovarian functions, not only the incidence of certain cancers increase, but also accumulate greater percentage amounts of visceral fat than younger women with increases in weight, especially during the early postmenopausal period. ${ }^{137}$ This is further supported by the evidence that menopause disproportionately enhances the accumulation of visceral fat. ${ }^{138,142}$

\section{Practical aspects of losing weight}

Behavioral modifications and lifestyle changes are essential for the successful induction of weight loss, maintenance of weight at the desired level, and eliminating excess future CVD risks. All obese and overweight patients should be educated about the risks of excess weight, and individuals should be encouraged to select a diet that contains low in saturated fat and refined carbohydrates that he or she can afford and adhere to for the long term. For example, a balanced, fiber-rich diet that contains less than $25 \%$ fat, about $20 \%$ to $25 \%$ protein, and $50 \%$ to $55 \%$ complex carbohydrates seems to help most patients to lose weight and to maintain a healthy weight.

Motivation to lose weight is exceptionally important for long-term success. In this regard, frequent self-monitoring with weighing twice a month, feedback, and family, peer, and group support are important, especially for the weight main-

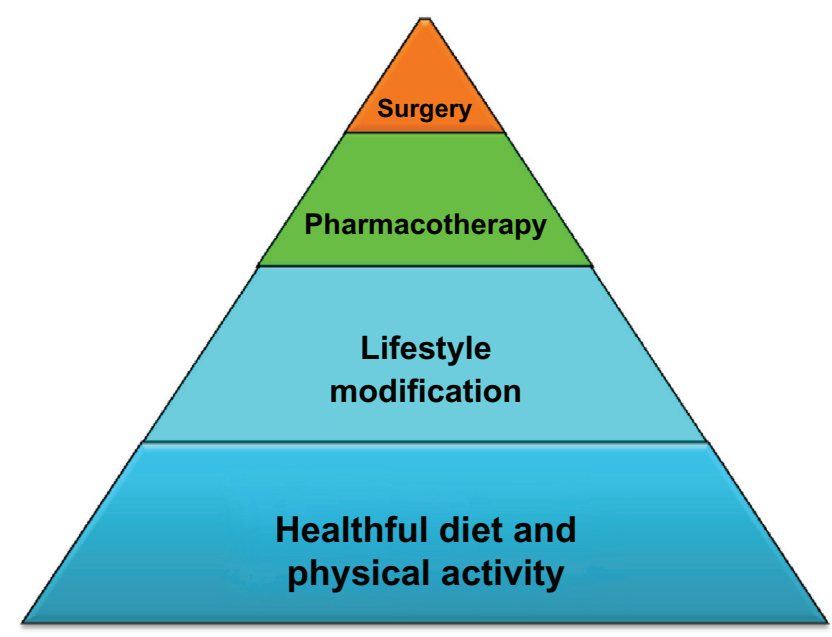

Figure I The pyramid of management of overweight and obese patients.

tenance, weight once excess pounds have been shed. This is true, whether the weight loss is achieved via diet and physical activity, using weight loss medications or bariatiric surgery.

In addition to engaging in weight-bearing physical activities, having healthy breakfasts and a relatively light evening meal seem to help to control hunger and maintain euglycemia and weight loss. Figure 1 illustrates the pyramid of obesity management. As per the current guidelines: (1) medications are indicated for less than $10 \%$ of all obese patients; and (2) bariatric surgery for less than $5 \%$. Thus, the vast majority of 
overweight and obese patients can be managed well with motivation, education, and lifestyle changes (diet and exercise).

Regular, higher levels of physical activity are useful for the maintenance of weight loss. The average energy expenditure from normal day-to-day physical activity is about $2800 \mathrm{kcal} /$ week, which corresponds to about 45 to 60 minutes of moderate-intensity physical activity each day. Fast walking is the easiest and most convenient, safe, and cost effective form of physical activity. During the normal routine workday or by using a walking exercise regimen, one should aim to walk between 8000 and 12,000 steps per day. Increasing the workand leisure-related physical activity to improve the overall physical well-being is becoming more important with modernization of our lifestyles. ${ }^{103}$ Limiting sedentary activities, in particular watching television or working with computers, would also help maintain weight loss that has been achieved.

\section{Conclusion}

A variety of evidence suggests that intra-abdominal fat deposits significantly correlate with metabolic abnormalities observed in overweight and obese patients; ${ }^{140-142}$ thus, identifying and reducing visceral fat content in such patients can decrease their future CVD risk. It is also possible that, in addition to playing a causal role in the pathophysiology of insulin resistance and metabolic syndrome, excess visceral adipose tissue also represents a marker of chronic inflammation, and an inherent dysfunctional fat metabolism by which excess energy is unable to be stored as subcutaneous fat. ${ }^{143}$ These abnormalities would exacerbate oxidative stress, hypertriglyceridemia, inflammation, and atherogenesis and further increase the accumulation of hepatic and visceral fat.

Nevertheless, many do not seem to grasp the gravity of the nationwide increased incidence of obesity and T2D, which are reaching pandemic proportions in North America. In addition to heightening the public awareness of the health risks associated with overweight and obesity, health care workers need to emphasize individualized healthy weightmanagement tips, healthy eating, physical activities, and the mainstream medical care to gain the attention of politicians and the public.

Compared to the use of WC and the waist-to-hip ratio, BMI has limitations, especially among Asians, in determining those who are at risk of insulin resistance and metabolic syndrome. The use of changes in WC seem to be the most cost effective predictor of changing visceral adipose tissues, metabolic syndrome, and the future development of CVD. Deposition of visceral fat as measured with increasing abdominal girth provides useful and important information of visceral fat accumulation and increased risk of CVD. Accumulation of excess visceral body fat, rather than subcutaneous fat, is the main correlate of metabolic abnormalities of obesity and one of the best predictors of future CVD.

More than one-third of adults and $18 \%$ of all teens and adolescents in the US are obese, making obesity one of the greatest public health issues in North America. Obesity is associated with multiple comorbidities, and can also be the cause of other diseases such as cancer. In addition, obesity enhances the severity of sleep apnea, hypertension, and dyslipidemia, which further increases cardiovascular risk. Thus, at every patient encounter, clinicians should encourage their patients to engage in healthful lifestyle changes in terms of improving diet and physical activities.

Several medications to assist in weight reduction have been approved, and others are in development. Nevertheless, all these drugs have significant adverse effects. Thus, clinicians must be vigilant in discussing pros and cons as well as warning signs of toxicity of these weight loss medications with their patients. Invasive surgical options, albeit effective, are costly and associated with some morbidity. They should be reserved for the markedly obese patients and those who are obese with severe comorbidities (ie, obsese and not fit) who cannot or failed to reduce their weight through other means. With the range of surgical and pharmacological options available to patients, prescribing clinicians must have a good understanding of not only the efficacy, but more importantly the adverse effects of these therapeutic options and when to refer such patients, so that their patients would receive the best options and cost effective treatments.

\section{Disclosure}

The author reports no conflicts of interest in this work.

\section{References}

1. Dawber TR, Meadors GF, Moore FE Jr. Epidemiological approaches to heart disease: the Framingham study. Am J Public Health Nations Health. 1951;41:279-281.

2. Kannel WB. Some lessons in cardiovascular epidemiology from Framingham. Am J Cardiol. 1976;37(2):269-282.

3. Block JP, DeSalvo KB, Fisher WP. Are physicians equipped to address the obesity epidemic? Knowledge and attitudes of internal medicine residents. Prev Med. 2003;36(6):669-675.

4. Story MT, Neumark-Stzainer DR, Sherwood NE, et al. Management of child and adolescent obesity: attitudes, barriers, skills, and training needs among health care professionals. Pediatrics. 2002;110(1 Pt 2):210-214.

5. Stice E, Shaw H, Marti CN. A meta-analytic review of obesity prevention programs for children and adolescents: the skinny on interventions that work. Psychol Bull. 2006;132(5):667-691.

6. Christakis NA, Fowler JH. The spread of obesity in a large social network over 32 years. $N$ Engl J Med. 2007;357(4):370-379.

7. Carmo C, Sá H, Xavier da Cunha MF, Campos M. Alpha-interferon renal toxicity. Nefrologia. 2005;25(6):718-719. 
8. Sa HS, Cho HY, Kang SW. Optical coherence tomography of idiopathic polypoidal choroidal vasculopathy. Korean J Ophthalmol. 2005;19(4): 275-280.

9. Ogden CL, Flegal KM, Carroll MD, Johnson CL. Prevalence and trends in overweight among US children and adolescents, 1999-2000. JAMA. 2002;288(14):1728-1732.

10. Sá H, Freitas L, Mota A, Cunha F, Marques A. Primary antiphospholipid syndrome presented by total infarction of right kidney with nephrotic syndrome. Clin Nephrol. 1999;52(1):56-60.

11. Flegal KM, Carroll MD, Ogden CL, Johnson CL. Prevalence and trends in obesity among US adults, 1999-2000. JAMA. 2002;288(14): $1723-1727$.

12. Katzmarzyk PT. The Canadian obesity epidemic: an historical perspective. Obes Res. 2002;10(7):666-674.

13. Wang Y, Mi J, Shan XY, Wang QJ, Ge KY. Is China facing an obesity epidemic and the consequences? The trends in obesity and chronic disease in China. Int J Obes (Lond). 2007;31(1):177-188.

14. Duncan DT, Wolin KY, Scharoun-Lee M, Ding EL, Warner ET, Bennett GG. Does perception equal reality? Weight misperception in relation to weight-related attitudes and behaviors among overweight and obese US adults. Int J Behav Nutr Phys Act. 2011;8:20.

15. Shields M, Carroll MD, Ogden CL. Adult obesity prevalence in Canada and the United States. NCHS Data Brief. 2011;56:1-8.

16. Tremblay MS, Pérez CE, Ardern CI, Bryan SN, Katzmarzyk PT. Obesity, overweight and ethnicity. Health Rep. 2005;16(4): 23-34.

17. Flegal KM, Carroll MD, Ogden CL, Curtin LR. Prevalence and trends in obesity among US adults, 1999-2008. JAMA. 2010;303(3) 235-241

18. HHS.gov. Prevalence of obesity. Office of Minority Health Department of Health and Human Services. 2010. http://www.minorityhealth.hhs. gov/templates/content.aspx $10=6456$.

19. Colditz GA, Willett WC, Stampfer MJ, et al. Weight as a risk factor for clinical diabetes in women. Am J Epidemiol. 1990;132(3):501-513.

20. Kolotkin RL, Crosby RD. Psychometric evaluation of the impact of weight on quality of life-lite questionnaire (IWQOL-lite) in a community sample. Qual Life Res. 2002;11(2):157-171.

21. Manson JE, Willett WC, Stampfer MJ, et al. Body weight and mortality among women. N Engl J Med. 1995;333(11):677-685.

22. Fabricatore AN, Wadden TA, Rohay JM, et al. Weight loss expectations and goals in a population sample of overweight and obese US adults. Obesity (Silver Spring). 2008;16(11):2445-2450.

23. Nicklas BJ, Penninx BW, Cesari M, et al. Association of visceral adipose tissue with incident myocardial infarction in older men and women the Health, Aging and Body Composition Study. Am J Epidemiol. 2004;160(8):741-749.

24. Kuk JL, Katzmarzyk PT, Nichaman MZ, Church TS, Blair SN, Ross R. Visceral fat is an independent predictor of all-cause mortality in men Obesity (Silver Spring). 2006;14(2):336-341.

25. Cnop M, Havel PJ, Utzschneider KM, et al. Relationship of adiponectin to body fat distribution, insulin sensitivity and plasma lipoproteins: evidence for independent roles of age and sex. Diabetologia. 2003; 46(4):459-469.

26. Despres JP, Lemieux I, Prud'homme D. Treatment of obesity: need to focus on high risk abdominally obese patients. $B M J$. 2001;322(7288): 716-720.

27. Brandle M, Zhou H, Smith BR, et al. The direct medical cost of type 2 diabetes. Diabetes Care. 2003;26(8):2300-2304.

28. Gilmer TP, O'Connor PJ, Rush WA, et al. Predictors of health care costs in adults with diabetes. Diabetes Care. 2005;28(1):59-64.

29. Vijan S, Hayward RA, Langa KM. The impact of diabetes on workforce participation: results from a national household sample. Health Serv Res. 2004;39(6 Pt 1):1653-1669.

30. Betz MD. Enriching Health: Pathways to Complementary Therapies. Bloomington IN: Authorhouse; 2006.

31. Daviglus ML. Health care costs in old age are related to overweight and obesity earlier in life. Health Aff (Millwood). 2005;24 Suppl 2:W5R97-100.
32. Popkin BM, Kim S, Rusev ER, Du S, Zizza C. Measuring the full economic costs of diet, physical activity and obesity-related chronic diseases. Obes Rev. 2006;7(3):271-293.

33. Hojgaard B, Olsen KR, Sogaard J, Gyrd-Hansen D, Sorensen TI. Obesity related health care costs assessed from BMI or waist circumference secondary publication. Ugeskr Laeger. 2009;171(43):3068-3071. Danish.

34. Bigaard J, et al. Waist circumference, BMI, smoking, and mortality in middle-aged men and women. Obes Res. 2003;11(7):895-903.

35. Pouliot $\mathrm{MC}$ et al. Waist circumference and abdominal sagittal diameter: best simple anthropometric indexes of abdominal visceral adipose tissue accumulation and related cardiovascular risk in men and women. Am J Cardiol. 1994;73(7):460-468.

36. Wimalawansa SJ. Thermogenesis - based interventions for obesity and type 2 diabetes. Expert Reviewers of Endocronology and Metabolism. (In Press).

37. Lewiński A, Brona A, Lewnadowski K, Skowrońska-Jóźwiak E, Milewicz A. In contrast to matrix metalloproteinases, serum adiponectin concentrations increase after radioiodine treatment of thyrotoxicosis. Thyroid Res. 2012;5(1):12.

38. Memon S,A Memon MM. Spectrum and immediate outcome of seizures in neonates. J Coll Physicians Surg Pak. 2006;16(11):717-720.

39. A S, T I, A M, T W, J P. The arterial vascularization of the stomach fundus of human fetuses. Folia Morphol (Warsz). 1999;58(3):191-198.

40. Korner J, Aronne LJ. The emerging science of body weight regulation and its impact on obesity treatment. J Clin Invest. 2003;111(5):565-570.

41. Aronne LJ. Therapeutic options for modifying cardiometabolic risk factors. Am J Med. 2007;120(3 Suppl 1):S26-S34.

42. Willett WC, Manson JE, Stampfer MJ, et al. Weight, weight change, and coronary heart disease in women. Risk within the 'normal' weight range. JAMA. 1995;273(6):461-465.

43. Colditz GA, Willett WC, Rotnitzky A, Manson JE. Weight gain as a risk factor for clinical diabetes mellitus in women. Ann Intern Med. 1995;122(7):481-486.

44. Ogden CL, Carroll MD, Kit BK, Flegal KM. Prevalence of obesity and trends in body mass index among US children and adolescents, 1999-2010. JAMA. 2012;307(5):483-490.

45. Koebnick C, Smith N, Coleman KJ, et al. Prevalence of extreme obesity in a multiethnic cohort of children and adolescents. J Pediatr. 2010;157(1):26-31.

46. Flegal KM, Carroll MD, Kuczmarski RJ, Johnson CL. Overweight and obesity in the United States: prevalence and trends, 1960-1994. Int J Obes Relat Metab Disord. 1998;22(1):39-47.

47. Ogden CL, Carroll MD, Curtin LR, McDowell MA, Tabak CJ, Flegal KM. Prevalence of overweight and obesity in the United States, 1999-2004. JAMA. 2006;295(13):1549-1555.

48. Wilson PW, D'Agostino RB, Sullivan L, Parise H, Kannel WB. Overweight and obesity as determinants of cardiovascular risk: the Framingham experience. Arch Intern Med. 2002;162(16): 1867-1872.

49. Schiller JS, Lucas JW, Ward BW, Peregoy JA. Summary Health Statistics for US Adults: National Health Interview Survey, 2010. Hyattsville, MD: US Department of Health and Human Services, Centers for Disease Control and Prevention, National Center for Health Statistics; 2012. Available from: http://www.cdc.gov/nchs/data/series/ sr_10/sr10_252.pdf. Accessed February 18, 2013.

50. Flegal KM, Carroll MD, Kit BK, Ogden CL. Prevalence of obesity and trends in the distribution of body mass index among US adults, 1999-2010. JAMA. 2012;307(5):491-497.

51. Pascot A, Lemieux I, Prud'homme D, et al. Reduced HDL particle size as an additional feature of the atherogenic dyslipidemia of abdominal obesity. J Lipid Res. 2001;42(12):2007-2014.

52. Lemieux I, Pascot A, Prud'homme D, et al. Elevated C-reactive protein: another component of the atherothrombotic profile of abdominal obesity. Arterioscler Thromb Vasc Biol. 2001;21(6): 961-967.

53. Couillard C, Bergeron N, Prud'homme D, et al. Postprandial triglyceride response in visceral obesity in men. Diabetes. 1998;47(6): 953-960. 
54. The Practical Guide: Identification, Evaluation, and Treatment of Overweight and Obesity in Adults. Bethesda, MD: National Institutes of Health; 2000. Available from: http://www.nhlbi.nih.gov/guidelines/ obesity/prctgd_c.pdf. Accessed February 13, 2013.

55. Marks R, Allegrante JP. Body mass indices in patients with disabling hip osteoarthritis. Arthritis Res. 2002;4(2):112-116.

56. Pi-Sunyer FX. Medical hazards of obesity. Ann Intern Med. 1993; 119 (7 Pt 2):655-660.

57. Browning JD, Szczepaniak LS, Dobbins R, et al. Prevalence of hepatic steatosis in an urban population in the United States: impact of ethnicity. Hepatology. 2004;40(6):1387-1395.

58. De Waele B, Vanmierlo B, Van Nieuwenhove Y, Delvaux G. Impact of body overweight and class I, II and III obesity on the outcome of acute biliary pancreatitis. Pancreas. 2006;32(4):343-345.

59. Tsai CJ, Leitzmann MF, Willett WC, Giovannucci EL. Prospective study of abdominal adiposity and gallstone disease in US men. Am J Clin Nutr. 2004;80(1):38-44.

60. Alvarez-Blasco F, Botella-Carretero JI, San Millán JL, EscobarMorreale HF. Prevalence and characteristics of the polycystic ovary syndrome in overweight and obese women. Arch Intern Med. 2006;166(19): 2081-2086.

61. López-Casasnovas G, Rivera B, Currais L, editors. Health and Economic Growth: Findings and Policy Implications. Massachusetts: The MIT Press; 2005.

62. Bloom DE, Canning D, Sevilla J. The Effect of Health on Economic Growth: Theory and Evidence. World Dev. 2004;32(1):1-13.

63. Ogden CL, Carroll MD, Flegal KM. High body mass index for age among US children and adolescents, 2003-2006. JAMA. 2008;299(20): 2401-2405.

64. Mei Z, Scanlon KS, Grummer-Strawn LM, Freedman DS, Yip R, Trowbridge FL. Increasing prevalence of overweight among US low-income preschool children: the Centers for Disease Control and Prevention pediatric nutrition surveillance, 1983 to 1995. Pediatrics. 1998;101(1):E12.

65. Ogden CL, Troiano RP, Briefel RR, Kuczmarski RJ, Flegal KM, Johnson CL. Prevalence of overweight among preschool children in the United States, 1971 through 1994. Pediatrics. 1997;99(4):E1.

66. Austin SB, Melly SJ, Sanchez BN, Patel A, Buka S, Gortmaker SL. Clustering of fast-food restaurants around schools: a novel application of spatial statistics to the study of food environments. Am J Public Health. 2005;95(9):1575-1581.

67. Lobstein T, Jackson-Leach R. Estimated burden of paediatric obesity and co-morbidities in Europe. Part 2. Numbers of children with indicators of obesity-related disease. Int $J$ Pediatr Obes. 2006;1(1):33-41.

68. Carr A, Samaras K, Thorisdottir A, Kaufmann GR, Chisholm DJ, Cooper DA. Diagnosis, prediction, and natural course of HIV-1 protease-inhibitor-associated lipodystrophy, hyperlipidaemia, and diabetes mellitus: a cohort study. Lancet. 1999;353(9170): 2093-2099.

69. Carr A, Samaras K, Burton S, et al. A syndrome of peripheral lipodystrophy, hyperlipidaemia and insulin resistance in patients receiving HIV protease inhibitors. AIDS. 1998;12(7):F51-F58.

70. Alberti KG, Zimmet P, Shaw J. Metabolic syndrome - a new worldwide definition. A Consensus Statement from the International Diabetes Federation. Diabet Med. 2006;23(5):469-480.

71. Grundy SM. Obesity, metabolic syndrome, and cardiovascular disease. $J$ Clin Endocrinol Metab. 2004;89(6):2595-2600.

72. Hales CN, Barker DJ. The thrifty phenotype hypothesis. Br Med Bull. 2001;60:5-20.

73. Hales CN, Desai M, Ozanne SE. The Thrifty Phenotype hypothesis: how does it look after 5 years? Diabet Med. 1997;14(3): 189-195.

74. Leibel RL, Rosenbaum M, Hirsch J. Changes in energy expenditure resulting from altered body weight. NEJM.1995; 332(10):621-628.
75. Janjua NZ, Mahmood B, Islam MA, Goldenberg RL. Maternal and early childhood risk factors for overweight and obesity among low-income predominantly black children at age five years: a prospective cohort study. J Obes. 2012;2012:457173.

76. Hales CN, Barker DJ. Type 2 (non-insulin-dependent) diabetes mellitus: the thrifty phenotype hypothesis. Diabetologia. 1992;35(7):595-601.

77. Wells JC. The thrifty phenotype hypothesis: thrifty offspring or thrifty mother? J Theor Biol. 2003;221(1):143-161.

78. Höring HU, Mehnert H. Pathogenesis of type 2 (non-insulin-dependent) diabetes mellitus: candidates for a signal transmitter defect causing insulin resistance of the skeletal muscle. Diabetologia. 1993;36(3): $176-182$.

79. Jaquet D, Deghmoun S, Chevenne D, Czernichow P, Lévy-Marchal C. Low serum adiponectin levels in subjects born small for gestational age: impact on insulin sensitivity. Int J Obes (Lond). 2006;30(1): $83-87$.

80. Lévy-Marchal C, Czernichow P. Small for gestational age and the metabolic syndrome: which mechanism is suggested by epidemiological and clinical studies? Horm Res. 2006;65 Suppl 3:123-130.

81. Mi J, Cheng H, Zhao XY, Hou DQ, Chen FF, Zhang KL. Developmental origin of metabolic syndrome: interaction of thinness at birth and overweight during adult life in Chinese population. Obes Rev. 2008;9 Supp1 1:91-94.

82. Kerkhof GF, Leunissen RW, Hokken-Koelega AC. Early origins of the metabolic syndrome: role of small size at birth, early postnatal weight gain, and adult IGF-I. J Clin Endocrinol Metab. 2012;97(8): 2637-2643.

83. Leunissen RW, Kerkhof GF, Stijnen T, Hokken-Koelega A. Timing and tempo of first-year rapid growth in relation to cardiovascular and metabolic risk profile in early adulthood. JAMA. 2009;301(21): 2234-2242.

84. Ozanne SE, Jensen CB, Tingey KJ, Storgaard H, Madsbad S, Vaag AA. Low birthweight is associated with specific changes in muscle insulin-signalling protein expression. Diabetologia. 2005; 48(3):547-552.

85. Santomauro AT, Boden G, Silva ME, et al. Overnight lowering of free fatty acids with Acipimox improves insulin resistance and glucose tolerance in obese diabetic and nondiabetic subjects. Diabetes. 1999;48(9): 1836-1841.

86. Boden G, Shulman GI. Free fatty acids in obesity and type 2 diabetes: defining their role in the development of insulin resistance and beta-cell dysfunction. Eur J Clin Invest. 2002;32 Suppl 3:14-23.

87. Rizzoni D, Muiesan ML, Porteri E, et al. Vascular remodeling, macroand microvessels: therapeutic implications. Blood Press. 2009;18(5): 242-246.

88. Pinto A, Tuttolomondo A, Parrinello G, Paterna S, Di Chiara T, Licata G. Prevalence, topographic distribution, and pathogenesis of macro- and microangiopathic vascular lesions in patients with diabetes mellitus. Retrospective study. Minerva Cardioangiol. 1999;47(12):581-582. Italian.

89. Gallacher JE, Pickering J, Elwood PC, Bayer AJ, Yarnell JW, Ben-Shlomo Y. Glucoregulation has greater impact on cognitive performance than macro-vascular disease in men with type 2 diabetes: data from the Caerphilly study. Eur J Epidemiol. 2005;20(9): 761-768.

90. Alexander CM, Landsman PB, Teutsch SM, Haffner SM; Third National Health and Nutrition Examination Survey (NHANES III); National Cholesterol Education Program (NCEP). NCEP-defined metabolic syndrome, diabetes, and prevalence of coronary heart disease among NHANES III participants age 50 years and older. Diabetes. 2003;52(5): $1210-1214$.

91. Pittas AG, Lau J, Hu FB, Dawson-Hughes B. The role of vitamin D and calcium in type 2 diabetes. A systematic review and meta-analysis. $J$ Clin Endocrinol Metab. 2007;92(6):2017-2029. 
92. Power C, Miller SK, Alpert PT. Promising new causal explanations for obesity and obesity-related diseases. Biol Res Nurs. 2007;8(3): 223-233.

93. Yusuf S, Hawken S, Ounpuu S, et al. Obesity and the risk of myocardial infarction in 27,000 participants from 52 countries: a case-control study. Lancet. 2005;366(9497):1640-1649.

94. Bigaard J, Tjønneland A, Thomsen BL, Overvad K, Heitmann BL, Sørensen TI. Waist circumference, BMI, smoking, and mortality in middle-aged men and women. Obes Res. 2003;11(7) 895-903.

95. Janiszewski PM, Janssen I, Ross R. Does waist circumference predict diabetes and cardiovascular disease beyond commonly evaluated cardiometabolic risk factors? Diabetes Care. 2007;30(12): 3105-3109

96. Lemieux I, Pascot A, Couillard C, et al. Hypertriglyceridemic waist: a marker of the atherogenic metabolic triad (hyperinsulinemia; hyperapolipoprotein B; small, dense LDL) in men? Circulation. 2000;102(2):179-184.

97. Hawkins M, Rossetti S. Insulin resistance and its role in the pathogenesis of type 2 diabetes. In: Kahn CR, Weir GC, King G, Jacobson AM, Moses AC, Smith RJ, editors. Joslin's Diabetes Mellitus, $14^{\text {th }}$ ed. Boston, MA: Lippincott Williams \& Wilkins; 2005:425-448.

98. Riccardi G, Aggett P, Brighenti F, et al. PASSCLAIM - body weight regulation, insulin sensitivity and diabetes risk. Eur J Nutr. 2004 43 Suppl 2:II7-II46.

99. Baik I. Optimal cutoff points of waist circumference for the criteria of abdominal obesity: comparison with the criteria of the International Diabetes Federation. Circ J. 2009;73(11):2068-2075.

100. Smith SC Jr, Haslam D. Abdominal obesity, waist circumference and cardio-metabolic risk: awareness among primary care physicians, the general population and patients at risk - the Shape of the Nations survey. Curr Med Res Opin. 2007;23(1):29-47.

101. Sturm R, Ringel JS, Lakdawalla DN, et al. Obesity and Disability: The Shape of Things to Come. Santa Monica, CA: RAND Corporation 2007. Available from: http://www.rand.org/content/dam/rand/pubs/ research_briefs/2007/RAND_RB9043-1.pdf. Accessed February 22, 2013.

102. Alley DE, Chang VW, Doshi J. The shape of things to come: obesity, aging, and disability. LDI Issue Brief. 2008;13(3):1-4.

103. Misra A, Vikram NK, Gupta R, Pandey RM, Wasir JS, Gupta VP. Waist circumference cutoff points and action levels for Asian Indians for identification of abdominal obesity. Int J Obes (Lond). 2006;30(1): 106-111.

104. Li C, Ford ES, McGuire LC, Mokdad AH. Increasing trends in waist circumference and abdominal obesity among US adults. Obesity (Silver Spring). 2007;15(1):216-224.

105. Howel D. Waist circumference and abdominal obesity among older adults: patterns, prevalence and trends. PLoS One. 2012;7(10): e48528.

106. Carr DB, Utzschneider KM, Hull RL, et al. Intra-abdominal fat is a major determinant of the National Cholesterol Education Program Adult Treatment Panel III criteria for the metabolic syndrome. Diabetes. 2004;53(8):2087-2094.

107. Park YW, Zhu S, Palaniappan L, Heshka S, Carnethon MR, Heymsfield SB. The metabolic syndrome: prevalence and associated risk factor findings in the US population from the Third National Health and Nutrition Examination Survey, 1988-1994. Arch Intern Med. 2003;163(4):427-436.

108. Minocci A, Guzzaloni G, Marzullo P, et al. Abdominal fat index by ultrasound does not estimate the metabolic risk factors of cardiovascular disease better than waist circumference in severe obesity. Diabetes Metab. 2005;31(5):471-477.

109. McKeigue PM, Shah B, Marmot MG. Relation of central obesity and insulin resistance with high diabetes prevalence and cardiovascular risk in South Asians. Lancet. 1991;337(8738):382-386.
110. Dudeja V, Misra A, Pandey RM, Devina G, Kumar G, Vikram NK. BMI does not accurately predict overweight in Asian Indians in northern India. Br J Nutr. 2001;86(1):105-112.

111. Kusuma YS, Babu BV, Naidu JM. Chronic energy deficiency in some low socio-economic populations from South India: relationships between body mass index, waist-hip ratio and conicity index. Homo. 2008;59(1):67-79.

112. Ross R, Freeman J, Hudson R, Janssen I. Abdominal obesity, muscle composition, and insulin resistance in premenopausal women. J Clin Endocrinol Metab. 2002;87(11):5044-5051.

113. Bacha F, Saad R, Gungor N, Janosky J, Arslanian SA. Obesity, regional fat distribution, and syndrome $\mathrm{X}$ in obese black versus white adolescents: race differential in diabetogenic and atherogenic risk factors. J Clin Endocrinol Metab. 2003;88(6):2534-2540.

114. Prentki M, Nolan CJ. Islet beta cell failure in type 2 diabetes. J Clin Invest. 2006;116(7):1802-1812.

115. Pascotto M, Wei K, Micari A, Bragadeesh T, Goodman NC, Kaul S. Phasic changes in arterial blood volume is influenced by collateral blood flow: implications for the quantification of coronary stenosis at rest. Heart. 2007;93(4):438-443.

116. Després JP. Is visceral obesity the cause of the metabolic syndrome? Ann Med. 2006;38(1):52-63.

117. Mertens I, Van der Planken M, Corthouts B, Van Gaal LF. Is visceral adipose tissue a determinant of von Willebrand factor in overweight and obese premenopausal women? Metabolism. 2006;55(5):650-655.

118. Couillard C, Ruel G, Archer WR, et al. Circulating levels of oxidative stress markers and endothelial adhesion molecules in men with abdominal obesity. J Clin Endocrinol Metab. 2005;90(12): 6454-6459

119. Lamarche B, Tchernof A, Mauriège P, et al. Fasting insulin and apolipoprotein B levels and low-density lipoprotein particle size as risk factors for ischemic heart disease. JAMA. 1998;279(24):1955-1961.

120. Després JP, Lemieux I. Abdominal obesity and metabolic syndrome. Nature. 2006;444(7121):881-887.

121. Mechanick JI, Kushner RF, Sugerman HJ, et al; American Association of Clinical Endocrinologists; Obesity Society; American Society for Metabolic and Bariatric Surgery. Executive summary of the recommendations of the American Association of Clinical Endocrinologists, the Obesity Society, and American Society for Metabolic and Bariatric Surgery medical guidelines for clinical practice for the perioperative nutritional, metabolic, and nonsurgical support of the bariatric surgery patient. Endocr Pract. 2008;14(3):318-336.

122. Buchwald H, Avidor Y, Braunwald E, et al. Bariatric surgery: a systematic review and meta-analysis. JAMA. 2004;292(14): 1724-1737.

123. Buchwald H; Consensus Conference Panal. Consensus conference statement bariatric surgery for morbid obesity: health implications for patients, health professionals, and third-party payers. Surg Obes Relat Dis. 2005;1(3):371-381.

124. Mittelman SD, Van Citters GW, Kirkman EL, Bergman RN. Extreme insulin resistance of the central adipose depot in vivo. Diabetes. 2002;51(3):755-761.

125. Björntorp P. "Portal" adipose tissue as a generator of risk factors for cardiovascular disease and diabetes. Arteriosclerosis. 1990;10(4): 493-496

126. Flier JS. The adipocyte: storage depot or node on the energy information superhighway? Cell. 1995;80(1):15-18.

127. Szmitko PE, Teoh H, Stewart DJ, Verma S. Adiponectin and cardiovascular disease: state of the art? Am J Physiol Heart Circ Physiol. 2007;292(4):H1655-H1663.

128. Greenstein AS, Khavandi K, Withers SB, et al. Local inflammation and hypoxia abolish the protective anticontractile properties of perivascular fat in obese patients. Circulation. 2009;119(12):1661-1670.

129. Girn HR, Orsi NM, Homer-Vanniasinkam S. An overview of cytokine interactions in atherosclerosis and implications for peripheral arterial disease. Vasc Med. 2007;12(4):299-309. 
130. Kahn R, Buse J, Ferrannini E, Stern M; American Diabetes Association; European Association for the Study of Diabetes. The metabolic syndrome: time for a critical appraisal: joint statement from the American Diabetes Association and the European Association for the Study of Diabetes. Diabetes Care. 2005;28(9):2289-2304.

131. Hsu LA, Chang CJ, Wu S, et al. Association between functional variants of the ICAM1 and CRP genes and metabolic syndrome in Taiwanese subjects. Metabolism. 2010;59(12):1710-1716.

132. Weisberg SP, McCann D, Desai M, Rosenbaum M, Leibel RL, Ferrante AW Jr. Obesity is associated with macrophage accumulation in adipose tissue. J Clin Invest. 2003;112(12):1796-1808.

133. Côté $\mathrm{M}$, Mauriège $\mathrm{P}$, Bergeron $\mathrm{J}$, et al. Adiponectinemia in visceral obesity: impact on glucose tolerance and plasma lipoprotein and lipid levels in men. J Clin Endocrinol Metab. 2005;90(3):1434-1439.

134. Després JP. Inflammation and cardiovascular disease: is abdominal obesity the missing link? Int J Obes Relat Metab Disord. 2003; 27 Suppl 3:S22-S24.

135. Berg AH, Scherer PE. Adipose tissue, inflammation, and cardiovascular disease. Circ Res. 2005;96(9):939-949.

136. Matsuzawa Y. Therapy Insight: adipocytokines in metabolic syndrome and related cardiovascular disease. Nat Clin Pract Cardiovasc Med. 2006;3(1):35-42.
137. Pascot A, Lemieux S, Lemieux I, et al. Age-related increase in visceral adipose tissue and body fat and the metabolic risk profile of premenopausal women. Diabetes Care. 1999;22(9):1471-1478.

138. Zamboni M, Armellini F, Milani MP, et al. Body fat distribution in pre- and post-menopausal women: metabolic and anthropometric variables and their inter-relationships. Int J Obes Relat Metab Disord. 1992;16(7):495-504.

139. Arsenault BJ, et al. Visceral adipose tissue accumulation, cardiorespiratory fitness, and features of the metabolic syndrome. Arch Intern Med. 2007;167(14):1518-1525.

140. Smith JD et al. Visceral adipose tissue indicates the severity of cardiometabolic risk in patients with and without type 2 diabetes: results from the INSPIRE ME IAA study. J Clin Endocrinol Meta. 2012;97(5):1517-1525.

141. Despres JP, Lemieux I. Abdominal obesity and metabolic syndrome. Nature. 2006;444 (7121):881-887.

142. Tchernof A, Després JP. Sex steroid hormones, sex hormonebinding globulin, and obesity in men and women. Horm Metab Res. 2000;32(11-12):526-536.

143. Lemieux I. Energy partitioning in gluteal-femoral fat: does the metabolic fate of triglycerides affect coronary heart disease risk? Arterioscler Thromb Vasc Biol. 2004;24(5):795-797.
Research and Reports in Endocrine Disorders

\section{Publish your work in this journal}

Research and Reports in Endocrine Disorders is an international, peerreviewed, open access journal publishing original research, reports, reviews and commentaries on all areas of endocrinology, endocrine disorders and therapeutic interventions. The manuscript management system is completely online and includes a very quick and fair

\section{Dovepress}

peer-review system. Visit http://www.dovepress.com/testimonials.php to read real quotes from published authors. 